\title{
Expression of B-class MADS-box genes in response to variations in photoperiod is associated with chasmogamous and cleistogamous flower development in Viola philippica
}

\author{
Qiaoxia $\mathrm{Li}^{1}$, Qingdi Huo', Juan Wang ${ }^{1}$, Jing Zhao ${ }^{1,2}$, Kun Sun $^{1^{*}}$ and Chaoying $\mathrm{He}^{2^{*}}$
}

\begin{abstract}
Background: Some plants develop a breeding system that produces both chasmogamous (CH) and cleistogamous (CL) flowers. However, the underlying molecular mechanism remains elusive.

Results: In the present study, we observed that Viola philippica develops $\mathrm{CH}$ flowers with short daylight, whereas an extended photoperiod induces the formation of intermediate $\mathrm{CL}$ and $\mathrm{CL}$ flowers. In response to long daylight, the respective number and size of petals and stamens was lower and smaller than those of normally developed $\mathrm{CH}$ flowers, and a minimum of 14-h light induced complete $\mathrm{CL}$ flowers that had no petals but developed two stamens of reduced fertility. The floral ABC model indicates that B-class MADS-box genes largely influence the development of the affected two-whorl floral organs; therefore, we focused on characterizing these genes in V. philippica to understand this particular developmental transition. Three such genes were isolated and respectively designated as VpTM6-1, VpTM6-2, and VpPI. These were differentially expressed during floral development (particularly in petals and stamens) and the highest level of expression was observed in $\mathrm{CH}$ flowers; significantly low levels were detected in intermediate $\mathrm{CL}$ flowers, and the lowest level in $\mathrm{CL}$ flowers. The observed variations in the levels of expression after floral induction and organogenesis apparently occurred in response to variations in photoperiod.

Conclusions: Therefore, inhibition of the development of petals and stamens might be due to the downregulation of B-class MADS-box gene expression by long daylight, thereby inducing the generation of $\mathrm{CL}$ flowers. Our work contributes to the understanding of the adaptive evolutionary formation of dimorphic flowers in plants.
\end{abstract}

Keywords: Adaptive evolution, Dimorphic flower, Gene expression, MADS-box gene, Photoperiod, Viola philippica

\section{Background}

Flowers are typically composed of four organ types: sepals, petals, stamens, and carpels, which run from the outside of the flower to the center. The ABC model of flower development explains how three major function class genes (A-, B-, and C-class) specify the identity of the four floral organ types. A-class alone controls sepals,

\footnotetext{
*Correspondence: kunsun@163.com; chaoying@ibcas.ac.cn

1 Life Science College, Northwest Normal University, Anning East Road 967,

Anning, 730070 Lanzhou, Gansu, China

${ }^{2}$ State Key Laboratory of Systematic and Evolutionary Botany, Institute of Botany, Chinese Academy of Sciences, Nanxincun 20Xiangshan 100093 Beijing, China
}

(c) 2016 The Author(s). Open Access This article is distributed under the terms of the Creative Commons Attribution 4.0 International License (http://creativecommons.org/licenses/by/4.0/), which permits unrestricted use, distribution, and reproduction in any medium, provided you give appropriate credit to the original author(s) and the source, provide a link to the Creative Commons license, and indicate if changes were made. The Creative Commons Public Domain Dedication waiver (http://creativecommons.org/publicdomain/zero/1.0/) applies to the data made available in this article, unless otherwise stated.
A-class in combination with B-class controls petals, Bclass in combination with $\mathrm{C}$-class controls stamens, and C-class alone controls carpels $[1,2]$. A pair of MADSbox genes, APETALA3 (AP3) and PISTILLATA (PI) in Arabidopsis thaliana, and DEFICIENS (DEF) and GLOBOSA (GLO) in Antirrhinum majus, encodes B-function activity [3-6]. Mutations in either the AP3/DEF or PI/ GLO genes results in similar phenotypic variations, wherein petals are transformed into sepals, and stamens into carpels [7-9]. The B-class lineages apparently underwent duplications and subsequent functional divergence in some core eudicots, possibly playing a role in 
the diversification of floral morphology during evolution [10-16]. For example, in Solanaceae and Leguminosae, the PI lineage duplicated into two GLO-like genes (GLO1 and GLO2), and the AP3 lineage underwent a duplication event at the base of the core eudicots, giving rise to two $A P 3$-like lineages called the euAP3 and paleoAP3 genes [14-20]. The euAP3 genes include AP3/ $D E F$, and the paleoAP3 type genes were named TOMATO MADS BOX GENE 6 (TM6) genes, after the first isolated member from Solanum lycopersicum [21]. Although these paralogous genes are partially redundant, they have largely contributed to the development of stamens and petals. Interestingly, the TM6 lineage was subsequently lost in Arabidopsis and Antirrhinum [22]. In contrast, the AP3 lineage was lost in papaya, which now only contains TM6 [23]. These results indicate that it is possible to retain either or both of the AP3/TM6 paralogous pair and still produce flowers [22].

B-class MADS-box genes are not only involved in the specification of organ identity of petals and stamens, but also in the control of organ maturation. Knocking down AP3/PI at intermediate stages (stages 8-10) in Arabidopsis flowers induces petal-to-sepal transformations that gradually occur in consecutive buds. However, although stamens in these flowers retain their identity, they become increasingly underdeveloped and do not dehisce pollen [24]. Independent petal loss within the buttercup family (Ranunculaceae) is strongly associated with decreased or eliminated expression of a single floral organ identity gene, AP3-3 [25]. In rice, the B-class MADSbox gene, SUPERWOMAN1 (SPW1), specifies the identities of lodicules (equivalent to petals) and stamens. This was supported by the observation in the mutant of this gene, superwoman1-cleistogamy (spw1-cls), of normal stamens, where lodicules were transformed homeotically to lodicule-glume mosaic organs, thereby engendering cleistogamy [26]. The phenotypic effect observed in the downregulation of Medicago truncatula TM6 (MtTM6) activity involved a change in petal shape, as well as some stamens differentiating into filaments and anthers failing to produce pollen grains [14]. Furthermore, severely downregulating either Physalis floridana GLO2 (PFGLO2) or Physalis floridana TM6 (PFTM6) only results in poor pollen maturation $[15,16]$.

Several plants, including most species in the genus Viola within the family Violaceae are dimorphic cleistogamy plants capable of producing both open potential outcross and closed selfing flowers [27]. Two examples are such as Viola odorata [28, 29] and V. pubescens [30]. The open flowers are also called chasmogamous $(\mathrm{CH})$ flowers, while the closed flowers called cleistogamous (CL) flowers. CL flowers may be energetically less costly to produce, resulting in more resources available for seed production and disruption of locally adapted gene complexes. On the other hand, $\mathrm{CH}$ flowers produce genetically variable progeny favored in spatially or temporally heterogeneous habitats [31-33]. Therefore, the evolution of dimorphic flowers at a single event exhibits the highest fitness when each flower type is produced in the environment for which it is best suited [27]. Compared to $\mathrm{CH}$ flowers, $\mathrm{CL}$ petals are undeveloped and functional stamens become smaller and decreased in number. Moreover, $V$. odorata $\mathrm{CH}$ flowers are formed in response to short daylight, whereas CL flowers emerge in response to long daylight $[28,29]$. In $V$. pubescens, orthologous genes for gibberellins 20 oxidase (VGA20ox) and gibberellins 3 oxidase (VGA3ox) are upregulated in $\mathrm{CH}$ flowers compared to that in CL flowers, thereby indicating a role for gibberellins (GA) in the differential production of flower types [34]. However, the molecular mechanisms underlying this developmental transition are largely unknown in Viola. In the present study, we revealed the variations in the development of petals and stamens, which are the major affected floral organs in the formation of dimorphic flowers in $V$. philippica under different photoperiods. Furthermore, we investigated the potential role of B-class MADS-box genes in the development of the $\mathrm{CH}-\mathrm{CL}$ breeding system. Three B-class MADS-box genes were cloned and designated as VpTM6-1, VpTM6-2, and VPPI. We determined that the differential expression of these genes during late floral development under the different photoperiods was correlated to the development of $\mathrm{CH}$ and $\mathrm{CL}$ flowers, thus providing novel insights into the development and evolution of dimorphic flowers in plants.

\section{Results}

\section{Different types of floral morphology in V. philippica}

$V$. philippica could develop both $\mathrm{CH}$ and CL flowers, although the $\mathrm{CL}$ flowers were approximately five to six times smaller than $\mathrm{CH}$ flowers (Fig. 1). $\mathrm{CH}$ flowers had five large and showy petals, with the lowest protruding slightly at the base into a spur, and five stamens forming a cone surrounding the pistil. Each stamen had four pollen sacs, and the lowest two stamens had noticeable nectar glands attached to them (Fig. 1a, d, g, and j). CL flowers had two stamens without nectar glands, each stamen had two pollen sacs, and the five petals were all undeveloped (Fig. 1b, e, h, and j). In certain conditions, intermediate CL (inCL) flowers developed, and they displayed variable characteristics. Typical observations were: between one and three poorly developed petals, two to five developed stamens, with each stamen having two to four pollen sacs but no nectar glands (Fig. 1c, f, i, and j). In extreme cases, a few poorly developed stamens in inCL flowers had one pollen sac, or even no pollen sac and just a membranous appendage (Fig. $1 \mathrm{i}$ and $\mathrm{j}$ ). In addition, we found that the stamen length, anther length, 


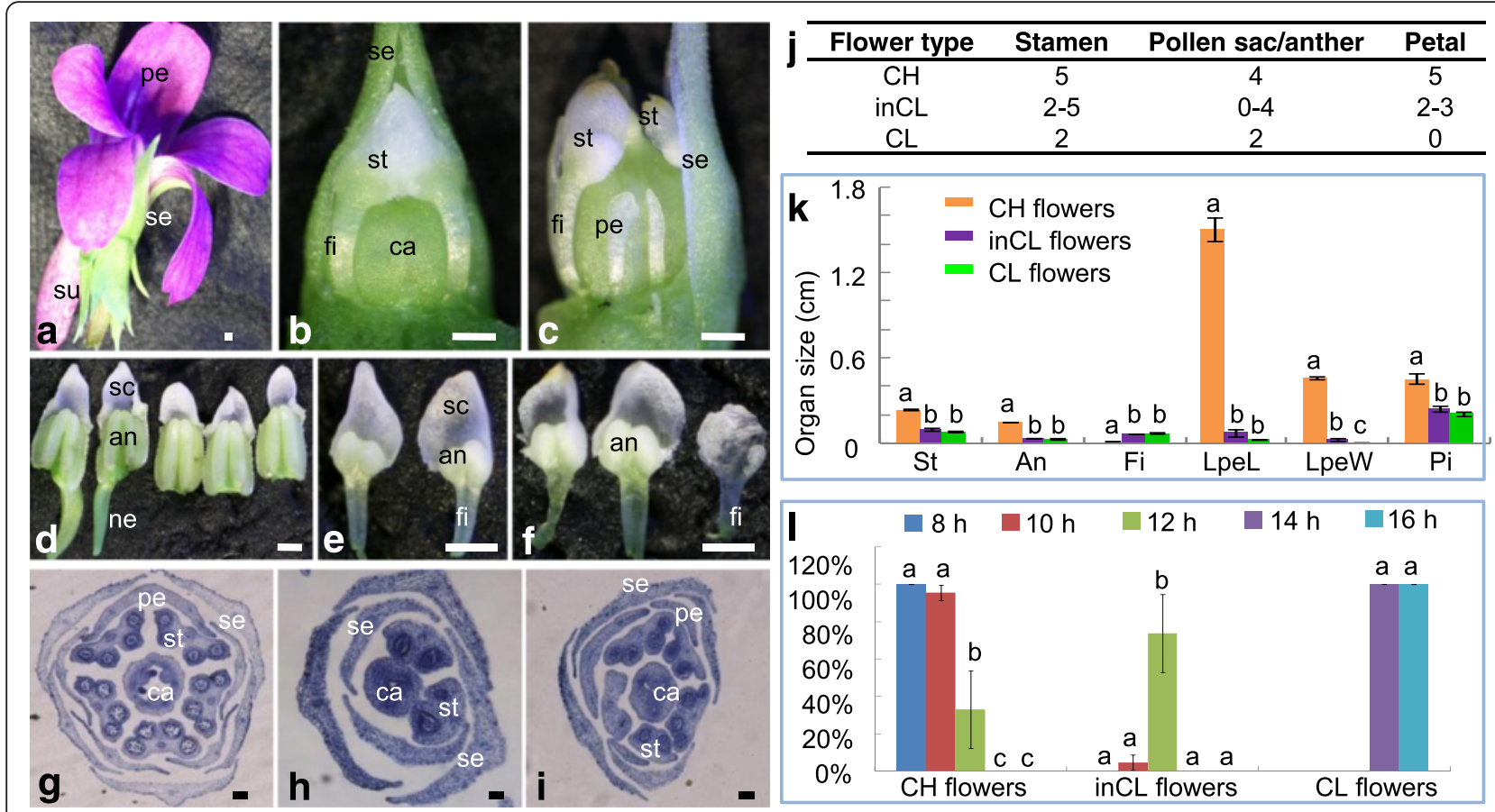

Fig. 1 Floral morphological variations under different photoperiods in V. philippica. a CH flower. b CL flower. c inCL flower. d CH flower stamens. Five stamens with invisible filament develop, showing distinct nectar glands. e CL flower stamens. Only two stamens with visible filament develop. $\mathbf{f}$ inCL flower stamens. Three to five stamens develop with visible filaments. g-i The cross sections of flowers. $\mathbf{g}$ CH flowers. Five stamens and five petals are observed. Each stamen has four pollen sacs. $\mathbf{h}$ CL flowers. Two stamens and no petal are detected. Each stamen has two pollen sacs. i inCL flowers. Two to three petals, and two to five stamens develop in these flowers. Each stamen has zero to four pollen sacs. The microsporogenesis in some stamens is inhibited. Bars $=500$ um (a-f). Bars $=200$ um (g and i), 100 um (h). se, sepal; pe, petal; su, spur; st, stamen; ca, carpel; an, anther; sc, stamen cap; fi, filament; ne, nectar gland. $\mathbf{j}$ Variations in the number of floral organs. $\mathbf{k}$ Variations in floral organ size. The length of stamens (St), anthers (An), filaments (Fi), lower petals (LpeL), and pistils (Pi), and the width of lower petals (LpeW) are measured. I The $\mathrm{CH}-\mathrm{CL}$ floral transition under different photoperiods. Standard errors are provided and lower-case letters (a, b, and c) indicate significant differences $(P<0.05)$

pistil length, lower petal length, and width of $\mathrm{CH}$ flowers were all significantly greater than those of CL and inCL flowers. Conversely, the filament of $\mathrm{CL}$ and inCL stamens was distinct compared to that of $\mathrm{CH}$ flowers, which was undetectable (Fig. 1d, e, f, and k). No homeosis of floral organs was observed in the $\mathrm{CH}-\mathrm{CL}$ transition.

\section{Photoperiods affect flower development in V. philippica}

Under natural conditions, $V$. philippica produced complete $\mathrm{CH}$ flowers in the early spring and a mixture of $\mathrm{CH}$ and inCL flowers in late spring and late autumn, whereas complete CL flowers developed in the summer and early autumn, suggesting that dimorphic flower development in $V$. philippica might be regulated by photoperiods. We thus set five photoperiods (8-, 10-, 12-, 14-, and 16-h daylight) to test this assumption. Results showed that three types of flowers developed under these conditions. Complete CL flowers were formed under long-day lights (14- and 16-h daylight), and $\mathrm{CH}$ flowers uniquely developed in 8-h daylight. At 10-12-h daylight, both $\mathrm{CH}$ and inCL flowers simultaneously developed and $>90 \%$ of the floral buds were $\mathrm{CH}$ flowers under a photoperiod of $10-\mathrm{h}$ daylight. The $\mathrm{CH} / \mathrm{inCL}+$ CLratio significantly decreased with longer photoperiods (Fig. 11), indicating that CL flower development was induced by long-day light. Therefore, different photoperiods may affect the development of petals and stamens, thus regulating the formation of different types of flower morphology in $V$. philippica. To further understand this formation, we next examined the floral organ initiation process.

\section{Organ initiation and development of different flower types in V. philippica}

$V$. philippica is a perennial plant with a $(2+3)$ phyllotaxis shoot system, similar to that in $V$. odorata [28]. Roughly five floral developmental stages were defined based on the position of phyllotaxis using a series of landmark events and observation with a scanning electron microscope. In general, the floral buds closer to the central tender leaf were determined to be relatively young. We comparatively depicted the floral development of $\mathrm{CH}$ flowers that developed under short 
daylights, as well as CL and inCL flowers that developed under long and transitional daylights. The first stage involved the generation of the floral meristem, whereas the second stage showed floral organogenesis. Four whorl floral organ primordia of $\mathrm{CH}$, as well as inCL and $\mathrm{CL}$ flowers, were observed in the floral meristem, indicating no obvious differences in the first and second stages in these three types of flowers (Fig. 2a, b, f, g, k, and 1). However, at the third stage, after four whorl organ primordia formation, $\mathrm{CH}$ flowers had five obvious petals and stamens, whereas CL flowers had two stamens, and other stamens and all petals only consisted of organ primordial structures (Fig. $2 \mathrm{c}$ and $\mathrm{m}$ ). There were two to five stamens, and at least lower petals that were poorly developed in inCL flowers (Fig. 2h). At the fourth stage (Fig. 2d, i, and n), four whorl floral organs of $\mathrm{CH}$ flowers continued to develop, and the style was higher than the stamens. The style of the CL and inCL flowers began to bend to the two fully developed stamens. At the fifth stage (Fig. 2e, j, and o), the nectar glands at the base of the two stamens began to appear in the $\mathrm{CH}$ flowers. The lower petals, side petals, or other stamens in the inCL flowers were poorly developed to some extent and later became more distinct, whereas five petals and the other three stamens (except for two big stamens) remained in the organ primordial state in the CL flowers (Fig. $2 \mathrm{j}$ and o). The filaments of $\mathrm{CL}$ and inCL stamens became relatively distinct (Fig. $2 j$ and $o$ ). The development of the three stamens and all petals were then completely arrested, and these floral organs remained as primordia in the CL flowers, which developed under long daylight. These comparative observations suggested that early floral development was indistinguishable between $\mathrm{CH}$ and $\mathrm{CL}$ flowers, whereas the morphological divergence leading to the dimorphic flowers occurred at stage 3 . This divergence was mainly attributable to the arrest of petal and stamen development in response to the extension of the photoperiod. Because the growth and differentiation of both petals and stamens were to some extent inhibited in the $\mathrm{CH}$ inCL-CL floral transition in $V$. philippica with extended photoperiods, we next investigated the role of B-class MADS-box genes in the development of these twowhorl floral organs.

\section{Isolation and sequencing analysis of B-class MADS-box genes in V. philippica}

Using a combination of homologous fragment amplification and rapid amplification of cDNA ends (RACE), we acquired the cDNA of the three genes as putative

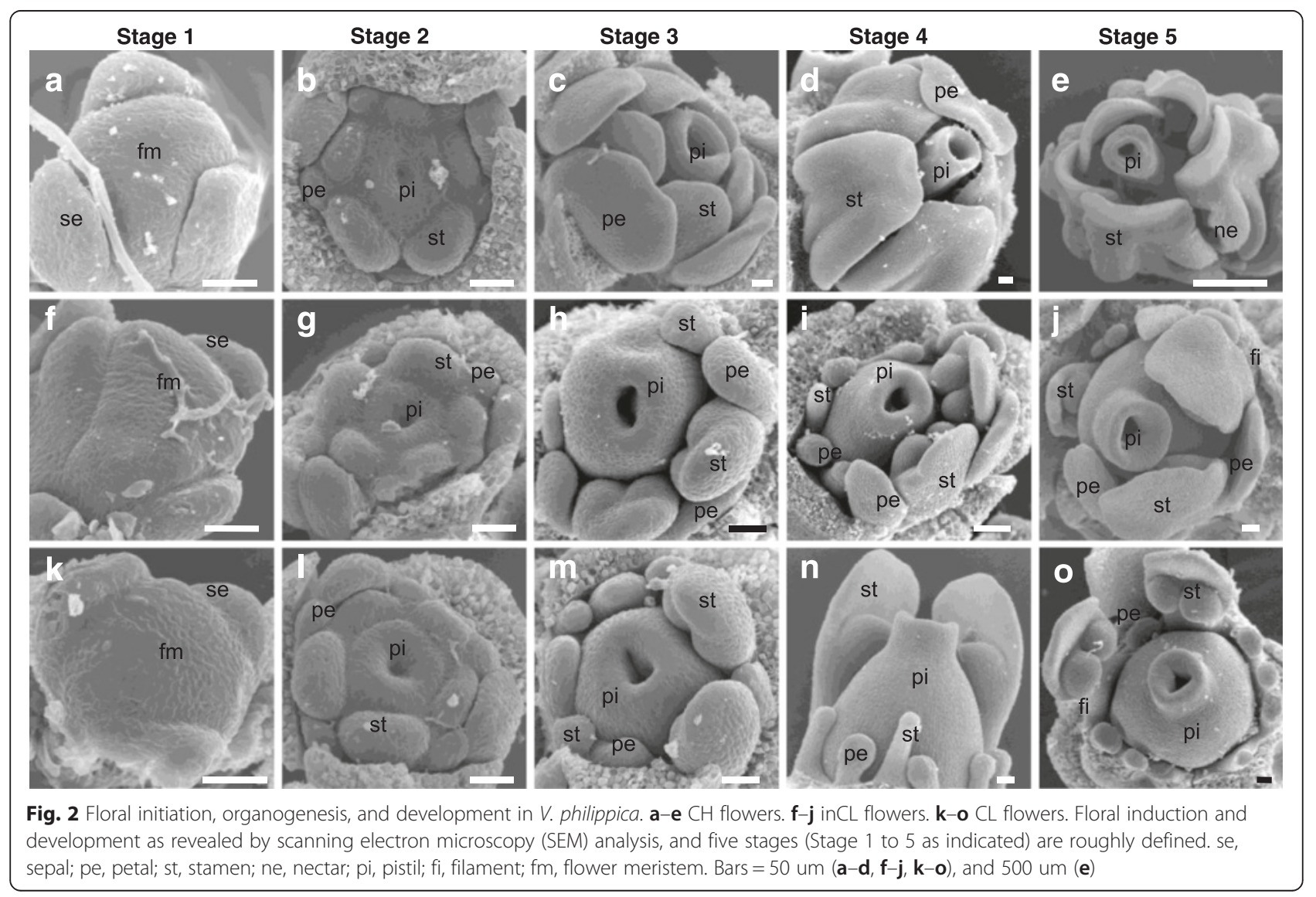


members of both AP3- and PI-lineages of the MADS-box genes. These two lineage genes usually feature a paleoAP3, euAP3, or PI motif at the end of the C-terminal region [17]. BLAST analysis identified two $V$. philippica AP3 paralogs that shared the highest sequence identity (66.8\% and $64.6 \%)$ at the amino acid level with putative
Petunia TM6 proteins (Additional file 1: Table S1), indicating that these were TM6-like genes, and were thus designated as VpTM6-1 and VpTM6-2. The open reading frame (ORF) of the VpTM6-1 and VpTM6-2 gene was 693 and 687 bp in length, respectively, and encoded predicted polypeptides of 230 and 228 amino

a ATGGGTCGTGGAAAGATTGAGATCAAGAAGATTGAGAATCCGACCAACAGGCAGGTGACCTACTCCAAGAGA 72

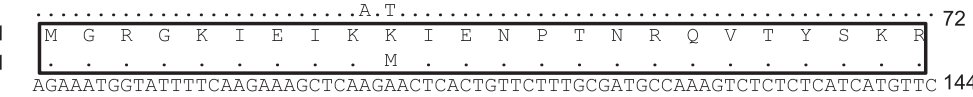

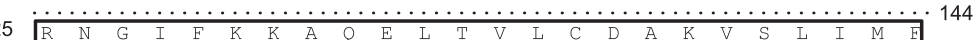

TCCAGTACTGGCAAATTCCATGAGTATATCACCCCATCCACTICO

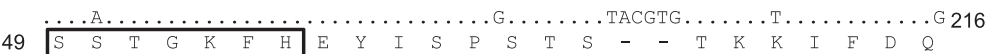

49

TACCAGAAGGCTTTAGGGGTAGATCTGTGGCAAACTCATTACGAGAGAATGCAAGAGAACCTGAGGAAACTG 282

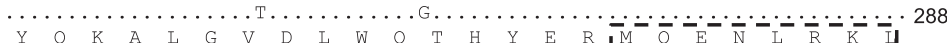

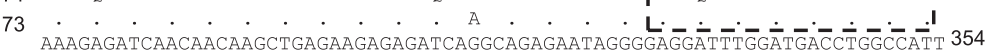

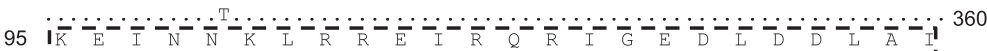

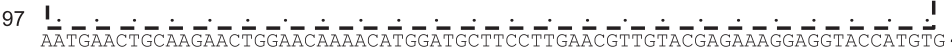

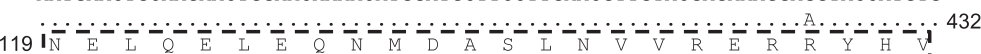

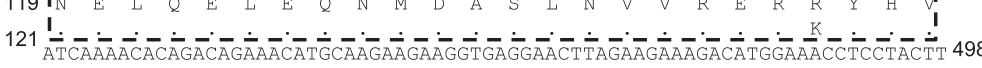

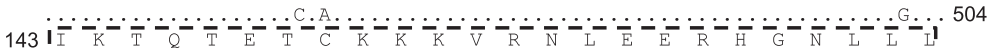

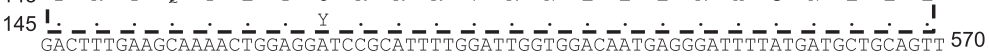

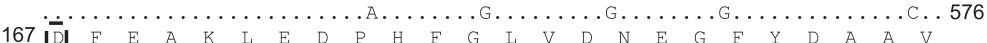

$169 \mathrm{I}$ I O E

GCACATGCAAATGGGGCATCCAACCTCTATGCTTTCCGCCTCCACCACCATAACCAACACCACCCTGATCAT 642

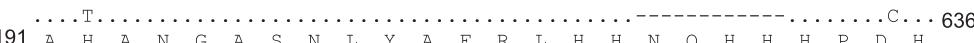

$\begin{array}{lllllllllllllllllllllllllll}191 & \text { A } & H & \text { A } & N & G & A & S & N & L & Y & A & F & R & L & H & H & N & Q & H & H & H & P & D & H\end{array}$

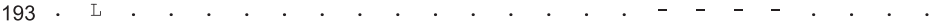

GAGCTCCACCATGGAGGAGGGTTTGCCTGCCACGAACTCCGCCTTCCTTGA

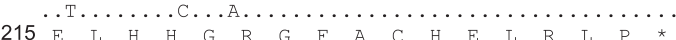

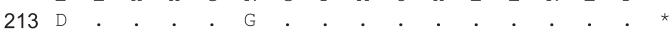

b Solanum lycopersicon LeDEF

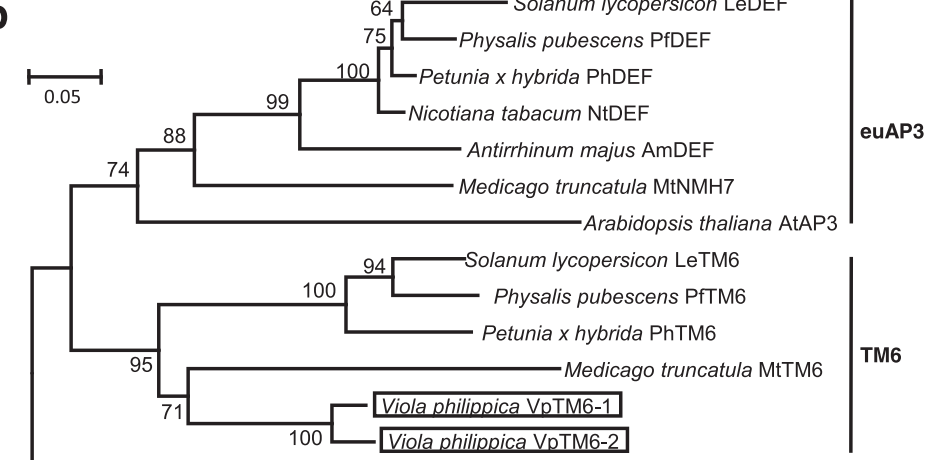

Oryza sativa OsMADS16

Fig. 3 Molecular characterization of AP3-like MADS-box genes in V. philippica. a The ORFs of the VpTM6 genes and its putative peptides. Gaps are introduced to show indels between the two paralogs. The sequences of VPTM6-1 are presented, and the identical sequences in VpTM6-2 are highlighted using dots. The star indicates the stop codon. The M, I, K, and C domains of the hypothetic VpTM6 proteins are indicated. The M domain is highlighted by solid boxes, and the $\mathrm{K}$ domain is indicated by dashed boxes. The region between $\mathrm{M}$ and $\mathrm{K}$ domains is the I domain, while the $\mathrm{C}$ domain is behind the $\mathrm{K}$ domain. The deleterious amino acid substitutions were highlighted in bold (for details, see Additional file 2: Table S2). b Neighbor-joining (NJ) tree of AP3-like genes. VPTM6-1 and VpTM6-1 are boxed. The accession numbers of other sequences used are LeTM6 (X60759.1), LeAP3 (DQ674532.1), PhTM6 (AF230704.1), PhDEF (X69946.1), MtTM6 (JN412097.1), MtNMH7 (JN412096.1), AtAP3 (NM115294.5), AmDEF (AB516402.1), NtDEF (X96428.1), PfDEF (KC174703.1), and PfTM6 (KC174704.1). OsMADS16 (AF077760.1) is used as outgroup. The species name is listed before the gene name. The numbers next to the nodes are bootstrap values. Multiple sequence alignment for the NJ tree is shown in Additional file 3: (Figure S1a) 
acids in length, respectively. Indels and single nucleotide polymorphisms (SNPs), including 41 nucleotide alteration positions were observed between these two cDNA sequences that resulted in 19 amino acid substitutions (Fig. 3a). Furthermore, these two paralogs shared $92.6 \%$ sequence identity at the amino acid level (Additional file 1: Table S1). The four domains (M, I, K and C) of MADS-domain proteins play an essential role in DNA-binding and protein-protein interaction $[35,36]$. Distribution of $2 \sim 10$ amino acid substitutions, including deletions, was observed in each domain of the hypothetical VpTM6 proteins (Fig. 3a). Most of the amino acid substitutions in VpTM6-2, compared to VpTM6-1, were of different properties, and two of these (K66M, and S63_T64insYV) were predicated to be deleterious in function (Fig. 3a; Additional file 2: Table S2). These divergences thereby suggested functional divergence of the two duplicates. Multiple sequence alignment of these two genes, together with representatives of some previously functionally inferred
AP3-like genes, showed that these two AP3 paralogous genes had a paleoAP3 motif instead of an euAP3 motif at the C-terminal end (Additional file 3: Figure S1a), further suggesting that these were putative TM6 orthologs. Phylogenetic analyses using the neighbor-joining (NJ) method further showed that these two AP3 paralogous genes were grouped together with previously reported TM6-like genes, such as the closely homologous genes from tomato, Petunia, and Physalis (Fig. 3b). These analyses clearly confirmed that the isolated two $V$. philippica AP3 lineage genes were TM6 orthologs. Unfortunately, AP3-lineage genes with the euAP3 motif were not isolated in the present study.

BLAST analysis also indicated that we isolated a PI putative ortholog in $V$. philippica, which we designated as $V p P I$. The ORF of the VpPI was 636 bp in length, and its cDNA encoded a predicted polypeptide of 211 amino acids in length (Fig. 4a) that was highly similar to Medicago PI (71.3 \% amino acid identity) and other PI orthologs from various plant species (Additional file 1: Table S1). Multiple

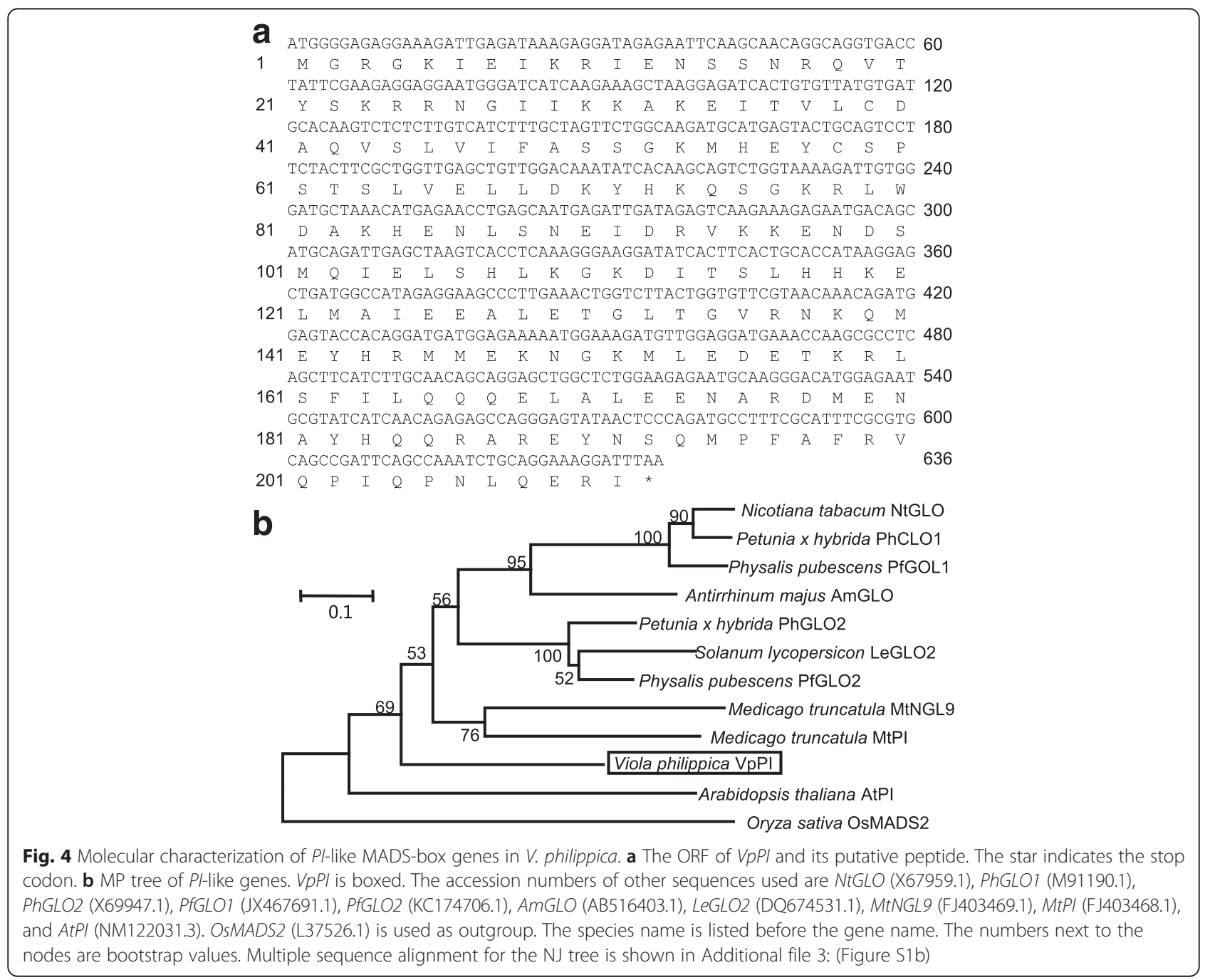


sequence alignment showed that the amino acid sequence of the $V$. philippica PI-homolog (VpPI) clearly had the $P I$ motif at the C-terminal region (Additional file 3: Figure S1b). Reconstruction of a NJ tree showed $V p P I$ clustering with PI (Fig. 4b). Therefore, VpTM6-1, $V p T M 6-2$, and VpPI belonged to the homologous sequences of the B-class MADS-box genes.

\section{Expression of VpTM6 and VpPI during floral induction and organogenesis}

Were the poorly developed or undeveloped petals and stamens of inCL and CL flowers in $V$. philippica related to variations in the expression of B-class MADS-box genes? To answer this question, we first examined the spatial and temporal patterns of expression during floral organogenesis and development of each flower type using in situ hybridization. Since the sequences of VpTM6-1 and VpTM6-2 were highly similar, a probe designed from VpTM6-2 was used in in situ hybridization to detect the expression of these two paralogs (designated as VpTM6). Results showed that VpTM6 and VpPI were continuously expressed from early stage (the second stage) to the later stage (the fifth stage) of floral organogenesis and development. At the floral organogenesis stage, $V p T M 6$ was not only expressed in the primordia that normally developed into petals, stamens and pistils in $\mathrm{CH}$, inCL, and $\mathrm{CL}$ flowers, but also in the primordia that either generated poorly developed petals and stamens or were retarded (Additional file 4: Figure S2a-l). In addition, in the later development stage of floral buds, VpTM6 was not only expressed in the developed petals and stamens in $\mathrm{CH}$, inCL, and CL flowers, but also in the poorly developed or undeveloped petals and stamens of inCL and CL flowers. VPPI shared a similar expression domain as VpTM6 during floral organogenesis and development of $\mathrm{CH}$, inCL, and $\mathrm{CL}$ flowers (Additional file 4: Figure $\mathrm{S} 2 \mathrm{~m}-\mathrm{x}$ ). Sense probes did not show any hybridization signals (Additional file 4: Figure S2y). We expected to observe distinct differences in the levels of expression of these genes between the fully developed and poorly or undeveloped floral organs in correlation to the three different types of flowers. However, no obvious difference in the spatial and temporal patterns of B-class gene expression was observed during floral organogenesis and development under any test conditions. The reason underlying these unexpected observations may be attributable to the decreased suitability of an in situ hybridization technique for quantification. Therefore, we investigated the expression of VpTM6-1, VpTM6-2, and VpPI using qRT-PCR.

\section{Late floral expression of $V p T M 6$ and $V p P I$ in response to various photoperiods}

To reveal the potential role of gene expression variation in response to photoperiods, we chose $\mathrm{CH}$, inCL, and
CL flower buds that corresponded to three photoperiods (10-, 12-, and 16-h daylight) for expression study. Two types of flower buds were used: the stage 3 flower buds (Fl1) that started to show distinct differences in morphology among $\mathrm{CH}$, inCL, and $\mathrm{CL}$ flowers; and the stage 4 to 5 flower buds, which were designated as Fl2. Mature flowers (Mf) and leaves were also included. Using Fl1 of the $\mathrm{CH}$ flowers as control (Fig. $5 \mathrm{a}-\mathrm{c}$ ), we determined that VpTM6-1, VpTM6-2, and VpPI were expressed at extremely low levels in leaves (Fig. $5 \mathrm{a}-\mathrm{c}$ ). In contrast, these genes were mainly expressed in floral tissues, and had a tendency to increase during flower development under all conditions (Fig. 5a-c). Moreover, VpTM6-1 and VpTM6-2 in each floral tissue under 10-h daylight were all higher than in those subjected to 12 - and 16-h daylight (Fig. 5a and b), thereby suggesting that the level of expression of VpTM6-1 and VpTM6-2 decreased as the duration of daylight was extended. A similar pattern of expression was observed in VpPI (Fig. 5c). These results indicated that the expression of the isolated MADS-box genes was predominantly expressed in floral organs, and hinted that the expression of these genes during late floral development stages might be regulated by photoperiods.

To investigate further, we examined the expression levels of VpTM6-1, VpTM6-2, and VPPI in floral organs of mature flowers (Fig. 5d-f). The floral organs, including sepals, petals, stamens, and pistils, corresponding to different photoperiods, were collected from $\mathrm{CH}$, inCL, and CL flowers. No expression of VpTM6-1 (Fig. 5d), VpTM6-2 (Fig. 5e), and VpPI (Fig. 5f) was detected in the sepals of all flower type, and expressed at a relatively low level in all the pistils. In contrast, these were highly expressed in the petals and stamens of all flowers (Fig. 5d-f). We also observed that the level of expression of VpTM6-1, VpTM6-2, and VPPI in the stamens and petals of the $\mathrm{CH}$ flowers were much higher than in the corresponding organs of inCL and CL flowers (Fig. $5 \mathrm{~d}-\mathrm{f}$ ). In particular, the level of expression of these genes significantly decreased in poorly developed stamens and petals of inCL flowers (Fig. 5d-f).

These observations indicated that the significant decrease in the expression of B-class MADS-box genes after floral organogenesis was induced by photoperiod extension, playing an essential role in the formation of CL flowers.

\section{Protein-protein interactions between VpTM6s and VpPI}

To distinguish the divergence of VpTM6-1 and VpTM6-2, we investigated protein-protein interactions (PPI) among the three B-class MADS-domain proteins using a yeast GAL4 two-hybrid system. Both activating His3 and LacZ reporters respectively enabling cell growth of the transformed yeast and the generation of the blue coloration in 

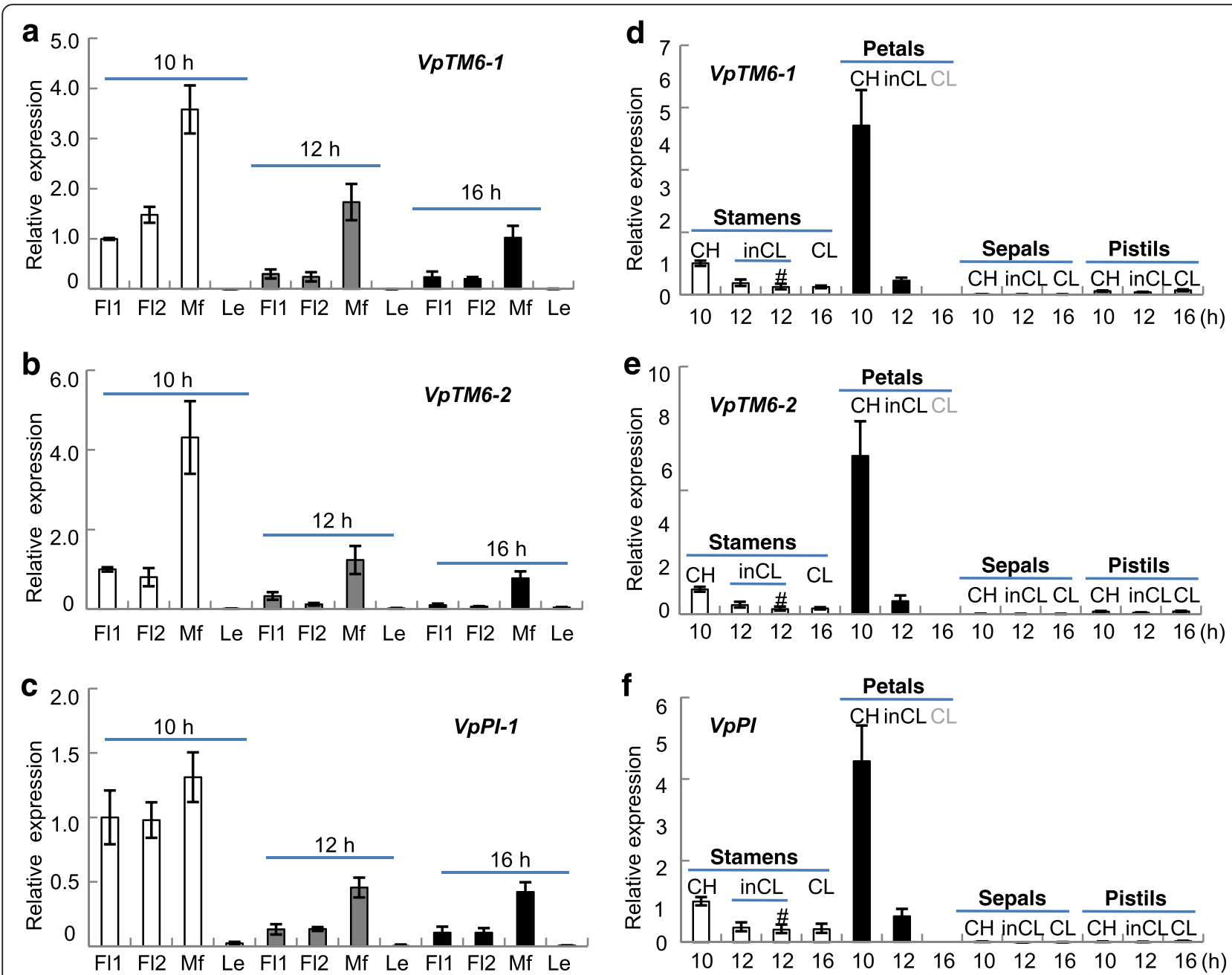

Fig. 5 The floral expression of B-class MADS-box genes in response to variations in photoperiod. a-c Relative expression of VpTM6-1, VpTM6-2, and $V P P I$ in flower buds and mature flowers. a VPTM6-1. b VPTM6-2. c VPPI. Gene expression in flower buds around the third stage (FI1), the fourth to fifth stages (FI2), mature flowers (Mf) and leaves (Le) under 10- (open columns), 12- (gray columns) and 16-h (black columns) daylight were evaluated using aRT-PCR. The gene expression in Fl1 under 10-h daylight was set to 1 . $\mathbf{d}$-f $\mathbf{f}$ Relative expression of B-class MADS-box genes in floral organs of mature flowers. d V PTM6-1. e V VTM6-2. f VpPI. Gene expression in stamens (open columns), petals (black columns), and pistils (gray columns) from $\mathrm{CH}$, inCL, and $\mathrm{CL}$ flowers under the indicated photoperiods were measured using qRT-PCR. No visible expression signal was detected in sepals under various conditions. \# indicates poorly developed stamens in inCL flowers. Gray " $C L$ " indicates that the petal was not collected from the $\mathrm{CL}$ flowers. The level of gene expression in the stamens of $\mathrm{CH}$ flowers subjected to 10-h daylight was set to 1. Three independent biological samples were used in all these analyses. Mean and standard errors are presented

the non-lethal ß-galactosidase assay were used to demonstrate PPIs. No toxicity and self-activation of these proteins in yeast were observed, and a dramatic difference in cell growth and $B$-galactosidase activity in yeast (Additional file 5: Figure S3) suggested that VpTM6-1 interacted strongly with VPPI in yeast, whereas the interaction between VpTM6-2 and VpPI was very weak, further implying a dramatic difference of transcriptional activity of the two heterodimmers. These results suggest functional divergence of the two VpTM6 paralogs. Nonetheless, no homodimerization of these B-class MADS-domain proteins was observed (Additional file 5: Figure S3).

\section{Discussion}

Some plants produce both $\mathrm{CH}$ and $\mathrm{CL}$ flowers in different ecological conditions during the growth cycle. Extensive studies have focused on how various ecological factors, including water, light intensity, photoperiod, soil fertility, and temperature could affect the $\mathrm{CH}-\mathrm{CL}$ mixed breeding system [30, 37-39]. The general conclusion is that dimorphic flower development might be the result of adaptive evolution. The present study investigated dimorphic flower development under different photoperiods in $V$. philippica, including its underlying molecular mechanisms. 


\section{Dimorphic flower development and photoperiod regulation}

The development of floral organs could be inhibited in nature; however, during the early developmental stage of flowers, all floral organ primordia are generally formed. For example, retardation or arrest of some floral organs after initiation occurs in most unisexual plants. Dioecious plants (such as white campion and Sorrel) and monoecious species (such as cucumber and London plant tree) all go through a hermaphroditic stage early in flower development, followed by differential abortion or arrest of sex organs, which can occur at various stages [40-43]. This phenomenon has also been observed in dimorphic cleistogamy plants. CL flowers of Lamium amplexicaule exhibit the least number of modifications, and no significant morphological differences are observed until pollen meiosis occurs compared to its $\mathrm{CH}$ flowers [44]. In the present study, no morphological differences at floral induction and organogenesis were detected in $V$. philippica. However, at later flower development stages, $\mathrm{CH}$ flowers featured normal flower structure, while petal and partial stamen development was retarded in CL flowers. In most cases, CL flowers had no petals and only a few fertile anthers. The arrest of floral organs is ubiquitous in nature for a variety of reasons [27, 28, 30, 40-43]. Similar to observations in temperate plant species $[27,34]$, the phenology of the two flower types in $V$. philippica is mainly determined by photoperiod. This phenomenon was also observed in $V$. odorata, in which $\mathrm{CH}$ flowers were formed in response to 11-h or less of daylight, CL flowers developed in response to 14-h or more of daylight, and inCL were produced during transitional periods [28]. Therefore, we confirmed that floral organ morphologic differentiation in $V$. philippica is determined during organogenesis after floral induction, and is influenced by photoperiod in dimorphic flower plants.

\section{Floral expression of VpTM6 and $V p P I$ in response to variations in photoperiod}

Genome-wide gene expression patterns from crossspecies microarray analysis of Cardamine kokaiensis of Brassicaceae has suggested that a substantial amount of genes, including petal and stamen developmental genes, are expressed differentially between $\mathrm{CH}$ and $\mathrm{CL}$ flowers [45]. However, the key regulatory gene in controlling the $\mathrm{CH}-\mathrm{CL}$ transition has not been identified. In the present study, the floral organs most affected in the $\mathrm{CH}-\mathrm{CL}$ transition as the photoperiod was extended were the petals and stamens. The floral ABC model indicates that B-class MADS-box genes determine the development of the two types of floral organs [1, 7, 46]. Modification of these genes either in terms of sequence or expression in various plants leads to the morphological diversification of related floral organs [13, 14, 25, 47-52]. To understand the molecular switches related to this CH-CL transition, we investigated these genes in $V$. philippica. Three B-class MADS-box genes, VpTM6-1, VpTM6-2, and $V p P I$ were isolated. The coding sequence variation of these B-class gene homologs does not immediately suggest any functional novelties relative to those in nondimorphic flower model plants, such as Arabidopsis and Petunia. Nonetheless, the expression of these genes was significantly altered in $\mathrm{CH}, \mathrm{CL}$, and inCL flower development. In line with no distinguishable differences during early flower development and no observed floral homeosis, these genes shared a relatively similar expression pattern during floral organogenesis of $\mathrm{CH}, \mathrm{CL}$, and inCL flowers. However, in the later flower development stage, where distinct floral morphology (particularly the size/number of petals and stamens) were observed in CL and inCL flowers, the expression of VpTM6-1, VpTM62 , and $V p P I$ in flowers (particularly in petals and stamens) significantly decreased in CL and inCL flowers, especially compared to $\mathrm{CH}$ flowers. The variations in expression pattern were concomitantly consistent with the floral organ divergence that generates $\mathrm{CH}$, inCL, and $\mathrm{CL}$ flowers in extended photoperiods. The downregulation of these B-class MADS-box genes occurred during the late developmental stages was not possible to alter the organ identity of petals and stamens, but might result in organ size reduction and developmental abortion. This was further supported by the observation that the extent of reduction in organ size/number was not strictly equivalent to the decrease extent of B-class gene expression in these organs (Additional file 6: Table S3), indicating that the drop in expression should not be a result of the lower proportion of petal/stamen tissues in CL and inCL flowers to those in $\mathrm{CH}$ flowers. Nonetheless, the $\mathrm{CH}-\mathrm{CL}$ transition, as an indirect result of the downregulation in the expression of these B-class genes, cannot be excluded. Given the postdevelopmental role of B-class MADS-box genes [24, 50-52], we therefore concluded that long daylight inhibited the development of petals and stamens by directly or indirectly inhibiting the expression of VpTM6-1, VpTM6-2, and VPPI genes to produce CL flowers.

B-class MADS-box genes, encoding bifunctional transcription factors, activate or repress a substantial number of downstream targets [24], thus acting as a contextdependent transcriptional switch that directs flower development: either floral organ identity, or postdevelopment. Since floral homeosis did not occur in the CH-CL transition, possible postdevelopmental mechanisms of Bclass genes in Viola were further discussed. In Arabidopsis, $A P 3$ and PI positively regulate the expression of SPOROCYTELESS/NOZZLE (SPL/NZZ) and NAP (for NAC-LIKE, ACTIVATED BY AP3/PI, also known as NO 
APICAL MERISTEM) [24, 53]. SPL/NZZ is necessary for the formation of anther walls, and is required during the late stages of stamen development for microsporogenesis and consequent pollen formation [54-57]. On the other hand, NAP is involved in the transition between cell division and cell expansion phases during the growth of petals and stamens [53]. AP3/PI also suppresses certain downstream genes, such as GNC and GNC-LIKE (GNL), that encode two GATA-type zinc finger proteins, which in turn regulate sugar response and nitrate metabolism genes, thereby providing a link between organ development and nutrient sensing [58]. Short photoperiods induce the expression of VGA2Oox and VGA3ox, which increases gibberellins that are also involved in $\mathrm{CH}-\mathrm{CL}$ flower development in V. pubescens [34]. Gibberellins regulate the expression of specific floral genes in Arabidopsis such as the B-class MADS-box genes [59, 60]. Therefore, upon perceiving regulatory signals such as photoperiod (or gibberellins), we assumed that the differential expression of these Viola B-class MADS-box genes might influence dimorphic flower development by regulating homologous genes $S P L / N Z Z, N A P$, and GNC, which in turn affects the growth and development of petals and stamens. However, further functional studies involving genetic manipulation of $V$. philippica should be conducted to verify this hypothesis.

\section{The novel role of B-class MADS-box genes in dimorphic flower development}

B-class MADS-box genes include both AP3 and PI lineages that evolved to play a primary role in petal and stamen development and in the establishment of stamen functionality $[12-16,18,61]$. Coding sequence variations that lead to different PPIs associated with these proteins play an essential role in this functional evolutionary process $[15,16]$, whereas altering its expression pattern facilitates the acquisition of additional functions, thereby leading to new floral morphologies [17-19, 25, 50-52]. The transcriptional regulation of these genes roughly includes the initiation of expression during early floral stages and the maintenance of expression through the majority of floral organ development $[6,9,46-48,62,63]$. When expression is affected during floral initiation, homeotic alterations usually occur, resulting in multiple corolla or calyces [7-9, 15, 64, 65]. However, when the expression is altered during late developmental stages, the maturation or function of the organs is affected [13-16, 24, 40-43]. Compared to previously identified B-class MADS-box genes [3-6], VpTM6-1, VpTM6-2, and VpPI in V. philippica shared a similar expression pattern during flower development, indicating that these genes may play a conserved role in establishing floral organ identity. However, we found that differential expression of these genes during late developmental stages of $\mathrm{CH}$ and $\mathrm{CL}$ flowers is regulated by variations in photoperiod, thereby suggesting a novel role for these B-class MADS-box genes in dimorphic flower development.

Floral morphology, such as petal size/shape instead of change of organ identity, could be regulated by artificial control of B-class gene expression, such as in M. truncatula [14] and tomato [13], whereas severely downregulating either PFGLO2 or PFTM6 only results in the production of immature pollen in $P$. floridana $[15,16]$. Interestingly, regulating gene expression to generate distinct floral morphology also occurs in nature, such as in the decrease in B-class MADS-box genes to generate $\mathrm{CL}$ flowers in $V$. philippica. The molecular mechanism underlying this regulation of B-class MADS-box genes in response to photoperiods in petals and stamens requires further investigation. Currently, at least two levels of divergence have been observed. VpTM6-1, VpTM6-2, and $V p P I$ are expressed at higher levels in petals than in stamens in $\mathrm{CH}$ flowers. However, this decrease in the level of expression was more extensive in petals than in stamens, correlating to the absence of petals and the reduction to two fertile stamens in CL flowers. Moreover, VpPI interacted strongly with VpTM6-1, but did weakly with VpTM6-2, which was indicative of VpTM6-1 and VpTM6-2 divergence in dimerization activity and transcriptional activity. Such differences in heterodimerization capabilities have been observed in species that harbor duplicated genes such as Petunia and Physalis $[12,15,16]$. Since a single amino acid change in the I doamin is sufficient to alter PI-like dimerization activity during maize domestication [66], that this type of divergence might result from extensive seuquence divergence of the two VpTM6 proteins, particularly the two deleterious alterations (K66M, and S63_T64insYV) in the I domain, should also be considered in understanding the functional divergence of B-class MADS-box genes in V. philippica.

\section{Conclusions}

The comprehensive investigation of floral MADS-box genes could facilitate better understanding of $\mathrm{CH}$ and CL flower development in V. philippica. Nevertheless, to our knowledge, we were the first time to reveal that the differential floral expression of B-class MADS-box genes after floral induction and organogenesis in response to variations in photoperiod is associated with the development of the $\mathrm{CH}-\mathrm{CL}$ breeding system in Viola. Our findings present new insight into the development and evolution of dimorphic flowers.

\section{Methods}

Plant materials and growth conditions

Seeds of $V$. philippica were collected and stored at the Northwest Normal University (Lanzhou, Gansu, China). They are available upon request. The seeds were 
sterilized by immersion in $30 \%$ sodium hypochlorite solution for $20 \mathrm{~min}$, and then rinsed three times with distilled water before sowing in triangular flasks containing MS (Murashige and Skoog) culture medium. After the fourth true leaves developed, the seedlings were transplanted to individual $100-\mathrm{mm}(0.5 \mathrm{~L})$ diameter plastic pots containing peat and vermiculite $(\mathrm{v} / \mathrm{v}=2: 1)$. The plants were grown at $22-28{ }^{\circ} \mathrm{C}$ under $8-, 10-, 12-, 14-$, and 16-h daylight, respectively, in a growth chamber. The temperature was kept by air-conditioners. The humidity was kept around $48 \%$, and light intensity was $116 \mu \mathrm{mol} \mathrm{m} \mathrm{m}^{-2} \mathrm{~s}^{-1}$. The plants under different daylight were grown in parallel on the different shelves. The daylight length was controlled by time controller in each cultivated shelf. To avoid the reciprocal influence, each shelf was enclosed by black cloth that was manually removed every day10:00 am for $8 \mathrm{~h}$ for ventilation.

\section{Flower morphology observation}

The morphology of flower buds was observed under a stereomicroscope (Olympus SZ61, Tokyo, Japan). The ratio of $\mathrm{CH}$, inCL, and $\mathrm{CL}$ flowers was evaluated under 8-, 10-, 12-, 14-, and 16-h daylight, respectively. One hundred plants were observed in each photoperiod, and about 200 flower buds were counted in each case. To measure floral organ size, 10 mature flowers of each type $(\mathrm{CH}$, inCL, and $\mathrm{CL})$ were analyzed. The images were captured using a camera linked to a stereomicroscope (Olympus SZ61, Tokyo, Japan).

\section{Scanning electron microscopy and histological analyses}

Flower buds at different stages were fixed in a 3:1 (v/v) ethanol:glacial acetic acid solution and kept at $4{ }^{\circ} \mathrm{C}$, dehydrated through an increasing ethanol gradient of up to $100 \%$ ethanol, and dried in a critical point drier. Samples were imaged using a scanning electron microscope (Hitachi S-450, Tokyo, Japan). For histological analyses, the whole green flower buds were dyed for $30 \mathrm{~h}$ using Love's hematoxylin to dark red color. Then, the dyed flower buds were washed in running water for $5 \mathrm{~h}$ to remove excess dye until these became blue. Finally, the blue flower buds were dehydrated through an increasing ethanol gradient, cleared using xylene, and embedded in Paraplast (Sigma P3683, St. Louis, Missouri, USA). Cross sections (7- $\mu \mathrm{m}$ thickness) of the flower buds were mounted on the slides with water at $40{ }^{\circ} \mathrm{C}$. The wax was cleared from the slides by washing with $100 \%$ xylene. The images of the cleared slides were finally photographed under a Leica microscope (DMI4000B, Wetzlar, Germany).

\section{Sequence isolation}

The cDNA fragments of the targeted genes were isolated using degenerate primers (Additional file 7: Table S4) that were designed based on the conserved regions of the APETALA3 (AP3) and PISTILLATA (PI) orthologs from various plant species in GenBank (http://www.ncbi.nlm.nih.gov/). The full-length cDNA was assembled using $3^{\prime} / 5^{\prime}$-rapid amplification of cDNA ends (RACE). Universal 3' and 5' PCR primers were supplied by the SMARTer ${ }^{\text {Th }}$ cDNA Library Construction Kit (Clontech, Mountain View, California, USA). After the RACE experiments, the full-length cDNA was amplified by routine RT-PCR using gene-specific primers (Additional file 7: Table S4). The cycling program consisted of an initial denaturation at $94{ }^{\circ} \mathrm{C}$ for $5 \mathrm{~min}$, followed by 35 cycles at $94{ }^{\circ} \mathrm{C}$ for $30 \mathrm{~s}, 55^{\circ} \mathrm{C}$ (degenerate primers) or $68{ }^{\circ} \mathrm{C}$ (gene-specific primers) for $30 \mathrm{~s}, 72{ }^{\circ} \mathrm{C}$ for $30 \mathrm{~s}$, and a final extension of $72{ }^{\circ} \mathrm{C}$ for $10 \mathrm{~min}$.

\section{Sequence divergence evaluation and phylogenetic analysis}

Neutral or deleterious amino acid mutations were predicted by PROVEAN, the protein variation effect analyzer with default parameter setting (http://provean.jcvi.org/ index.php). The amino acid sequences of these genes were aligned using CLUSTALW1.81 under default settings with manual adjustments. Gaps were introduced for proper alignment. The neighbor-joining phylogeny trees using protein sequences were constructed using MEGA5 [67]. Bootstrap values were based on 1,000 replicates.

\section{qRT-PCR}

The plant growth cycle of $V$. philippica was too long, few floral buds developed under 8-h daylight. Therefore, stages 3, 4, and 5 floral buds, young leaves, and floral organs of mature flowers were respectively collected under 10-, 12- and 16-h light period in the glasshouse. Total RNA was extracted using TRIzol reagent (TIANGEN, Beijing, China). For qRT-PCR analysis, a PrimeScript RT Reagent Kit (TaKaRa, Dalian, China), SYBR Premix EX Taq II (TaKaRa, Dalian, China), and gene-specific primers (Additional file 7: Table S4) were used. An 18S ribosomal RNA gene was used as internal reference (AB354544.1). The primers were designed using DNAMAN, and evaluating of their specificity and primer efficiency indicated that they were suitable for comparative qRT-PCR analysis (Additional file 8: Figure S4). The amplification conditions were $95{ }^{\circ} \mathrm{C}$ for $30 \mathrm{~s}$ for one cycle, followed by 40 cycles of $95{ }^{\circ} \mathrm{C}$ for $5 \mathrm{~s}$, and $60{ }^{\circ} \mathrm{C}$ for $30 \mathrm{~s}$. Three independent biological samples were used. Expression levels were calculated according to Livak and Schmittgen [68].

\section{RNA in situ hybridization}

Floral buds at various developmental stages were fixed in $4 \%(\mathrm{wt} / \mathrm{vol}=4 \mathrm{~g} / 100 \mathrm{~mL})$ paraformaldehyde and embedded in Paraplast (Sigma P3683, St. Louis, Missouri, USA). When ATG was set as 1, around 356-bp fragment 
of VpTM6-2 (positions 331-687) and VpPI (positions 236-591) was used as template for both sense and antisense probe synthesis using the DIG RNA labeling kit (Roche, Mannheim, Germany) and T7 RNA polymerase (Roche, Mannheim, Germany). Hybridization was performed as described by Javelle [69], with the alteration that we washed the slides at a temperature of $50{ }^{\circ} \mathrm{C}$. Sections of floral tissues of $\mathrm{CH}$, inCL and $\mathrm{CL}$ flowers were incubated in the same hybridization solution for each probe. Images were captured with a Leica microscope (DMI4000B, Wetzlar, Germany).

\section{Yeast two-hybrid analysis}

The ORFs of VpTM6-1, VpTM6-1, and VpPI were cloned into the pGADT7 or PGBKT7 vector (Clontech, Mountain View, California, USA). The co-transformed yeast cells of $\mathrm{BD}$ and $\mathrm{AD}$ fusion plasmids were selected by growth on SD plates lacking leucine (Leu) and tryptophan (Trp). Interactions were analyzed on the SD plates lacking Leu, Trp, adenine (Ade), and histidine (His), and further confirmed by the non-lethal $B$-galactosidase activity assay in the yeast strain AH109. Before checking PPIs, the toxicity and self-activation capability of these B-class MADS-domain proteins were checked. These experiments were performed according to Gong and He [70].

\section{Sequencing and primer information}

Sequencing of all constructs and primer synthesis were performed by Huada (Beijing, China). All primers used in this study are presented in Additional file 7: (Table S4).

\section{Additional files}

Additional file 1: Table S1. Protein sequence variation of AP3- (a) and PI-lineage (b) genes. (PDF $169 \mathrm{~kb}$ )

Additional file 2: Table S2. Amino acid divergence between the two VpTM6 paralogs. (PDF $177 \mathrm{~kb}$ )

Additional file 3: Figure S1. Multiple sequence alignment of B-class MADS-box genes. (PDF $312 \mathrm{~kb}$ )

Additional file 4: Figure S2. Gene expression during floral organogenesis and development. (PDF $590 \mathrm{~kb}$ )

Additional file 5: Figure S3. Protein-protein interactions in yeast. (PDF $180 \mathrm{~kb}$ )

Additional file 6: Table S3. The reduction extent of organ size and gene expression in $\mathrm{CH}-\mathrm{CL}$ transition. (PDF $336 \mathrm{~kb}$ )

Additional file 7: Table S4. The primers used in the present study. (PDF $252 \mathrm{~kb}$ )

Additional file 8: Figure S4. Primer evaluation for qRT-PCR. (PDF $342 \mathrm{~kb}$ )

\section{Abbreviations}

AP3, APETALA3; CDNA, complementary DNA; $C H$, chasmogamous; $C L$, cleistogamous. GLO, GLOBOSA; NJ, neighbor-joining; ORF, open reading frame; PI, PISTILLATA; PPI, protein-protein interaction; qRT-PCR, quantitative RT-PCR; RACE, rapid amplification of CDNA ends; SNP, single nucleotide polymorphism; TM6, TOMATO MADS BOX GENE 6

\section{Acknowledgements}

The assistance of Dr. PC Gong (State Key Laboratory of Systematic and Evolutionary Botany, Institute of Botany, Chinese Academy of Sciences) in yeast two-hybrid analysis and PROVEAN prediction is acknowledged.

\section{Funding}

This work was supported by the NSFC grants (31560066 and 31260054), the Young Teachers Improving Program from the Northwest Normal University (NWNU-LKQN-13-20), and the CAS/SAFEA International Partner Program for Creative Research Teams of "Systematic and Evolution Botany".

\section{Availability of data and materials}

All relevant supporting data can be found within the additional files accompanying this article. Sequence data described in this article can be found in GenBank (http://www.ncbi.nlm.nih.gov) under the accessions of KU318322 (VpTM6-1), KU318323 (VpTM6-2), and KU318324 (VpPI).

\section{Authors' contributions}

QXL, KS and CYH conceived and designed the work. KS identified plant species. QXL performed all experiments. JZ participated in the in situ hybridizations. QDH and JW involved in RNA extraction and expression study. QXL, KS and CYH analyzed the data. QXL, CYH and KS wrote the manuscript. All authors have read and approved the manuscript.

\section{Competing interests}

The authors declare that they have no competing interests.

Consent for publication

Not applicable.

Ethics approval and consent to participate

Not applicable.

Received: 23 February 2016 Accepted: 15 June 2016

Published online: 07 July 2016

\section{References}

1. Coen ES, Meyerowitz EM. The war of the whorls: genetic interactions controlling flower development. Nature. 1991:353:31-7.

2. Weigel D, Meyerowitz EM. The ABCs of floral homeotic genes. Cell. 1994;78:203-9.

3. Sommer H, Beltran JP, Huijser P, Pape H, Lonnig WE, Saedler H, SchwarzSommer Z. Deficiens, a homeotic gene involved in the control of flower morphogenesis in Antirrhinum majus: the protein shows homology to transcription factors. EMBO J. 1990;9:605-13.

4. Jack T, Brockman LL, Meyerowitz EM. The homeotic gene APETALA3 of Arabidopsis thaliana encodes a MADS box and is expressed in petals and stamens. Cell. 1992;68:683-97.

5. Trobner W, Ramirez L, Motte P, Hue I, Huijser P, Lonnig WE, Saedler $H$, Sommer H, Schwarz-Sommer Z. GLOBOSA: a homeotic gene which interacts with DEFICIENS in the control of Antirrhinum floral organogenesis. EMBO J. 1992;13:4693-704

6. Goto K, Meyerowitz EM. Function and regulation of the Arabidopsis floral homeotic gene. PISTILLATA. Genes Dev. 1994;8:1548-60.

7. Bowman JL, Smyth DR, Meyerowitz EM. Genes directing flower development in Arabidopsis. Plant Cell. 1989;1:37-52.

8. Hill JP, Lord EM. Floral development in Arabidopsis thaliana: a comparison of the wild type and the homeotic pistillata mutant. Can J Bot. 1989;67:2922-36.

9. Jack T, Fox GL, Meyerowitz EM. Arabidopsis homeotic gene APETALA3 ectopic expression: transcriptional and posttranscriptional regulation determine floral organ identity. Cell. 1994;76:703-16.

10. van der Krol AR, Brunelle A, Tsuchimoto S, Chua NH. Functional analysis of Petunia floral homeotic MADS box gene pMADS1. Genes Dev. 1993;7:1214-28.

11. Tsuchimoto S, Mayama T, van der Krol A, Ohtsubo E. The whorl-specific action of a Petunia class B floral homeotic gene. Genes Cells. 2000;5:89-99.

12. Vandenbussche M, Zethof J, Royaert S, Weterings K, Gerats T. The duplicated B-class heterodimer model: whorl-specific effects and complex genetic interactions in Petunia hybrid flower development. Plant Cell. 2004;16:741-54 
13. de Martino G, Pan I, Emmanuel E, Levy A, Irish VF. Functional analyses of two tomato APETALA3 genes demonstrate diversification in their roles in regulating floral development. Plant Cell. 2006;18:1833-45.

14. Roque E, Serwatowska J, Rochina MC, Wen JQ, Mysore KS, Yenush L, Beltrán J P, Caňas LA. Functional specialization of duplicated AP3-like genes in Medicago truncatula. Plant J. 2013;73:663-75.

15. Zhang JS, Li ZC, Zhao J, Zhang SH, Quan H, Zhao M, He CY. Deciphering the Physalis floridana double-layered-lantern 1 mutant provides insights into functional divergence of the GLOBOSA duplicates within the Solanaceae. Plant Physiol. 2014;164:748-64.

16. Zhang SH, Zhang JS, Zhao J, He CY. Distinct subfunctionalization and neofunctionalization of the B-class MADS-box genes in Physalis floridana. Planta. 2015;241:387-402.

17. Kramer EM, Dorit RL, Irish VF. Molecular evolution of genes controlling petal and stamen development: duplication and divergence within the APETALA3 and PISTILLATA MADS-box gene lineages. Genetics. 1998;149:765-83.

18. Vandenbussche M, Theissen G, Van de Peer Y, Gerats T. Structural diversification and neo-functionalization during floral MADS-box gene evolution by C-terminal frame shift mutations. Nucleic Acids Res. 2003;31:4401-9.

19. Kramer EM, Su HJ, Wu JM, Hu JM. A simplified explanation for the frameshift mutation that created a novel C-terminal motif in the APETALA3 gene lineage. BMC Evol Biol. 2006;6:30.

20. Benlloch R, Roque E, Ferrándiz C, Cosson V, Caballero T, Penmetsa RV, Beltrán JP, Cañas LA, Ratet P, Madueño F. Analysis of B function in legumes: PISTILLATA proteins do not require the PI motif for floral organ development in Medicago truncatula. Plant J. 2009;60:102-11.

21. Pnueli L, Abu-Abeid M, Zamir D, Nacken W, Schwarz-Sommer Z, Lifschitz E. The MADS box gene family in tomato: expression during floral development, conserved secondary structures and homology with homeotic genes from Antirrhinum and Arabidopsis. Plant J. 1991;1:255-66

22. Causier B, Castillo R, Xue Y, Schwarz-Sommer Z, Davies B. Tracing the evolution of the floral homeotic B- and C-function genes through genome synteny. Mol Biol Evol. 2010;27:2651-64.

23. Ackerman CM, Yu Q, Kim S, Paull RE, Moore PH, Ming R. B-class MADS-box genes in trioecious papaya: two paleoAP3 paralogs, CPTM6-1 and CPTM6-2, and a PI ortholog CPPI. Planta. 2008;227:741-53.

24. Wuest SE, O'Maoileidigha DS, Rae L, Kwasniewska K, Raganelli A, Hanczaryk K, Lohan, AJ, Loftus B, Graciet E, Wellmer F. Molecular basis for the specification of floral organs by APETALA3 and PISTILLATA. Proc Natl Acad Sci U S A. 2012:109:13452-7.

25. Zhang R, Guo C, Zhang WG, Wang PP, Li L, Duan XS, Zhao L, Shan HY, Hodges SA, Kramer EM, Ren Y, Kong HZ. Disruption of the petal identity gene APETALA3-3 is highly correlated with loss of petals within the buttercup family (Ranunculaceae). Proc Natl Acad Sci U S A. 2013:110:5074-9.

26. Yoshida H, Itoh Jl, Ohmori S, Miyoshi K, Horigome A, Uchida E, Kimizu M, Matsumura Y, Kusaba M, Satoh H, Nagato Y. Superwoman1-cleistogamy, a hopeful allele for gene containment in GM rice. Plant Biotech J. 2007:5:835-46.

27. Culley TM, Klooster MR. The cleistogamous breeding system: A review of its frequency, evolution, and ecology in angiosperms. Bot Rev. 2007:73:1-30.

28. Mayers AM, Lord EM. Comparative flower development in the cleistogamous species Viola odorata. I. A growth rate study. Am J Bot. 1983;70:1548-55

29. Mayers AM, Lord EM. Comparative flower development in the cleistogamous species Viola odorata. II.An organographic study. Am J Bot. 1983;70:1556-63.

30. Culley TM. Reproductive biology and delayed selfing in Viola pubescens (Violaceae), an understory herb with chasmogamous and cleistogamous flowers. Int J Plant Sci. 2002;163:113-22.

31. Mitchell-Olds T, Waller DM. Relative performance of selfed and outcrossed progeny in Impatiens capensis. Evolution. 1985:39:533-44.

32. Antlfinger AE. Field germination and seedling growth of $\mathrm{CH}$ and $\mathrm{CL}$ progeny of Impatiens capensis (Balsaminaceae). Am J Bot. 1986;73:1267-73.

33. Holsinger KE. Dispersal and plant mating systems: the evolution of selffertilization in subdivided populations. Evolution. 1986;40:405-13.

34. Wang Y, Ballard HE, McNally RR, Wyatt SE. Gibberellins are involved but not sufficient to trigger a shift between chasmogamous-cleistogamous flower types in Viola pubescens. J Torrey Bot Soc. 2013;140:1-8.
35. Immink RG, Kaufmann K, Angenent GC. The "ABC" of MADS domain protein behaviour and interactions. Semin Cell Dev Biol. 2010;21:87-93.

36. Theissen G. Development of floral organ identity: stories from the MADS house. Curr Opin Plant Biol. 2001:4:75-85.

37. Clavijo ERD, Jimenez MJ. Cleistogamy and chasmogamy in Ceratocapnos heterocarpa (Fumariaceae). Int J Plant Sci. 1993;154:325-33.

38. Corff $\lrcorner$. Effects of light and nutrient availability on chasmogamy and cleistogamy in an understory tropical herb, Calathea micans (Marantaceae). Am J Bot. 1993;80:1392-9.

39. Sigrist MR, Sazima M. Ruellia brevifolia (Pohl) Ezcurra (Acanthaceae): flowering phenology, pollination biology and reproduction. Braz J Bot. 2002;25:35-42.

40. Hardenack S, Ye D, Saedler H, Grant S. Comparison of MADS box gene expression in developing male and female flowers of the dioecious plant white campion. Plant Cell. 1994;6:1775-87.

41. Ainsworth C, Crossley S, Buchanan-Wollaston V, Thangavelu M, Parke J. Male and female flowers of the dioecious plant Sorrel show different patterns of MADS box gene expression. Plant Cell. 1995;7:1583-98

42. Kater MM, Franken J, Carney KJ, Colombo L, Angenent GC. Sex determination in the monoecious species cucumber is confined to specific floral whorls. Plant Cell. 2001;13:481-93.

43. Li Z, Liu G, Zhang J, Lu S, Yi S, Bao M. Cloning and characterization of paleoAP3-like MADS-box gene in London plane tree. Biol Plantarum. 2012;56:585-9.

44. Lord EM. Floral morphogenesis in Lamium amphlexicaule L. (Labiatae) with a model for the evolution of the cleistogamous flower. Botanical Gazette. 1982;143:63-72.

45. Morinaga SI, Nagano AJ, Miyazaki S, Kubo M, Demura T, Fukuda H, Sakai S, Hasebe M. Ecogenomics of cleistogamous and chasmogamous flowering: genome-wide gene expression patterns from cross-species microarray analysis in Cardamine kokaiensis (Brassicaceae). J Ecol. 2008:96:1086-97.

46. Krizek BA, Meyerowitz EM. The Arabidopsis homeotic genes APETALA3 and PISTILLATA are sufficient to provide the B class organ identity function. Development. 1996;122:11-22.

47. Hill TA, Day CD, Zondlo SC. Discrete spatial and temporal cis-acting elements regulate transcription of the Arabidopsis floral homeotic gene APETALA3. Development. 1998;125:1711-21.

48. Honma T, Goto K. The Arabidopsis floral homeotic gene PISTILLATA is regulated by discrete cis-elements responsive to induction and maintenance signals. Development. 2000;127:2021-30.

49. Stellari GM, Jaramillo MA, Kramer EM. Evolution of the APETALA3 and PISTILLATA lineages of MADS-box containing genes in basal angiosperms. Mol Biol Evol. 2004;21:506-19.

50. Kramer M, Holappa L, Gould B, Jaramillo MA, Setnikov D, Santiago PM. Elaboration of $B$ gene function to include the identity of novel floral organs in the lower eudicot Aquilegia. Plant Cell. 2007;19:750-66.

51. Sharma B, Guo C, Kong H, Kramer EM. Petal-specific subfunctionalization of an APETALA3 paralog in the Ranunculales and its implications for petal evolution. New Phytol. 2011;191:870-83.

52. Sharma B, Kramer EM. Sub- and neo-functionalization of APETALA3 paralogs have contributed to the evolution of novel floral organ identity in Aquilegia (columbine, Ranunculaceae). New Phytol. 2013:197:949-57.

53. Sablowski RWM, Meyerowitz EM. A homolog of NO APICAL MERISTEM is an immediate target of the floral homeotic genes APETALA3/PISTILLATA. Cell. 1998:92:93-103.

54. Schiefthaler U, Balasubramanian S, Sieber $\mathrm{P}$, Chevalier D, Wisman E, Schneitz K. Molecular analysis of NOZZLE, a gene involved in pattern formation and early sporogenesis during sex organ development in Arabidopsis thaliana. Proc Natl Acad Sci U S A. 1999:96:11664-9.

55. Yang WC, Ye D, Xu J, Sundaresan V. Molecular analysis of NOZZLE, a gene involved in pattern formation and early sporogenesis during sex organ development in Arabidopsis thaliana. Genes Dev. 1999;13:2108-17.

56. Ito T, Wellmer F, Yu H, Das P, Ito N, Alves-Ferreira M, Riechmann J, Meyerowitz EM. The homeotic protein AGAMOUS controls microsporogenesis by regulation of SPOROCYTELESS. Nature. 2004;15:356-60.

57. Liu XD, Huang J, Parameswaran S, Ito T, Seubert B, Auer M, Rymaszewski A, Jia GX. The SPOROCYTELESS/NOZZLE gene is involved in controlling stamen identity in Arabidopsis. Plant Physiol. 2009;151:1401-11.

58. Mara CD, Irish VF. Two GATA transcription factors are downstream effectors of floral homeotic gene action in Arabidopsis. Plant Physiol. 2008;147:707-18. 
59. Blazquez MA, Weigel D. Integration of floral inductive signals in Arabidopsis. Nature. 2000;404:889-92.

60. Yu H, Ito T, Zhao Y, Peng J, Kumar P, Meyerowitz EM. Floral homeotic genes are targets of gibberellin signaling in flower development. Proc Natl Acad Sci U S A. 2004;101:7827-32.

61. Rijpkema AS, Royaert S, Zethof J, van der Weerden G, Gerats T, Vandenbussche M. Analysis of the Petunia TM6 MADS box gene reveals functional divergence within the DEF/AP3 lineage. Plant Cell. 2006;18:1819-32.

62. Schwarz-Sommer Z, Hue I, Huijser P, Flor PJ, Hansen R, Tetens F, Lonnig WE, Saedler $\mathrm{H}$, Sommer $\mathrm{H}$. Characterization of the Antirrhinum floral homeotic MADS-box gene deficiens: evidence for DNA binding and auto regulation of its persistent expression throughout flower development. EMBO J. 1992;11:251-63.

63. Tilly JJ, Allen DW, Jack T. The CArG boxes in the promoter of the Arabidopsis floral organ identity gene APETALA3 mediate diverse regulatory effects. Development. 1998;125:1647-57.

64. Kanno A, Saeki H, Kameya T, Saedler H, Theißen G. Heterotopic expression of class B floral homeotic genes supports a modified ABC model for tulip (Tulipa gesneriana). Plant Mol Biol. 2003;52:831-41.

65. Hofer KA, Ruonala R, Albert VA. The double-corolla phenotype in the Hawaiian lobelioid genus Clermontia involves ectopic expression of PISTILLATA B-function MADS box gene homologs. EvoDevo. 2012;3:26.

66. Bartlett M, Thompson B, Brabazon H, Del Gizzi R, Zhang T, Whipple C. Evolutionary dynamics of floral homeotic transcription factor protein-protein interactions. Mol Biol Evol. 2016:33:1486-501.

67. Tamura K, Peterson D, Peterson N, Stecher G, Nei M, Kumar S. MEGA5: molecular evolutionary genetics analysis using maximum likelihood, evolutionary distance, and maximum parsimony methods. Mol Biol Evol. 2011:28:2731-9.

68. Livak KJ, Schmittgen TD. Analysis of relative gene expression data using real-time quantitative PCR and the $2^{-\Delta \Delta C T}$ method. Methods. 2001;25:402-8.

69. Javelle M, Marco CF, Timmermans M. In situ hybridization for the precise localization of transcripts in plants. J Vis Exp. 2011;57:3328.

70. Gong PC, Zhao M, He CY. Slow co-evolution of the MAGO and Y14 protein families is required for the maintenance of their obligate heterodimerization mode. PLoS One. 2014;1:e84842.

\section{Submit your next manuscript to BioMed Central and we will help you at every step:}

- We accept pre-submission inquiries

- Our selector tool helps you to find the most relevant journal

- We provide round the clock customer support

- Convenient online submission

- Thorough peer review

- Inclusion in PubMed and all major indexing services

- Maximum visibility for your research

Submit your manuscript at www.biomedcentral.com/submit 